\title{
EFICACIA E INEFICACIA DE LA COMUNICACIÓN HORIZONTAL EN LOS MOVIMIENTOS SOCIALES. CASO ANÁLISIS: "OPOSICIONES JUSTAS EN CATALUÑA 2011"
}

Carmen Echazarreta

Manel Vinyals

Teresa Gema Martín

Grupo de investigación ARPA

Carmen.echazarreta@udg.edu.

Material original autorizado para su primera publicación en la revista académica REDMARKA. Revista Digital de Marketing Aplicado

https://doi.org/10.17979/redma.2011.03.07.4737

Recibido: 14 Noviembre 2011

Aceptado 30 Noviembre 2011

\section{Resumen:}

Las redes sociales están generando un amplio entramado de comunicaciones, a distintos niveles y con distintos objetivos. En este artículo analizamos un caso concreto, fruto de la observación y el seguimiento de un grupo creado para la defensa de unas oposiciones justas para el acceso a la función pública de docentes para educación secundaria.

Se trata de un grupo creado como reacción a una serie de posibles irregularidades. Interesa observar tanto la creación del grupo, como las distintas fases que sigue la evolución, muy ligada a la efectividad de los procesos de comunicación, y la vinculación de estos últimos a las posibilidades de acción y resolución del conflicto que existe en la base del grupo.

Palabras clave: redes sociales, públicos, efectividad y inefectividad de la comunicación. 


\section{Abstract}

OBSERVING THE PROCESS OF COMMUNICATION IN SOCIAL GROUPS IN A CASE STUDY: OPPOSITION FAIR IN CATALONIA, 2011

Social networks are creating a wide network of communications, at different levels and with different objectives. In this paper we analyze a specific case, the result of observation and monitoring of a group created to defend just a competition for access to public secondary school-teachers. This is a group created in response to a number of possible irregularities. Interesting to observe both the creation of the group as the different phases that follows the evolution, linked to the effectiveness of communication processes, and linking the latter to the possibilities of action and conflict resolution at the base of the group.

Key words: social Networks, public theory, effectiveness and ineffectiveness of communications. 


\section{1.- Algunos datos sobre las redes sociales en el año 2011}

En el decurso del año 2011 han sido frecuentes los acontecimientos mediáticos atribuidos a las enormes posibilidades de comunicación que permiten las redes sociales. A nivel internacional, se calificó el movimiento social y político producido en Egipto y en Túnez como la Revolución Facebook. Fenómenos similares se han producido en Londres -england riots- , en España, 15 M, o los indignados, por democracia real, entre otros muchos, de mayor o menor alcance, y repercusión social.

Las comunicaciones a través de las redes sociales nos muestran con prontitud sus dotes comunicativos a favor de planteamientos democráticos, igualitarios y con una supuesta capacidad para conseguir y producir cambios en la sociedad; sin embargo, se trata de acontecimientos difíciles de analizar debido a la gran cantidad de elementos intervinientes. La primera dificultad, consiste en poder acceder, de primera mano, a los cauces por los que discurrió la comunicación, que en cada caso, se extendió en red.

Paralelamente a estos grandes hechos, que han destacado en varios titulares durante todo el año 2011, la comunicación a través de las redes sociales ha servido, también, para organizar a las personas que se habían encontrado, puntualmente, con similitudes en sus tipos de problemas. En este contexto, situamos el caso que analizamos en este artículo: "oposiciones justas en Cataluña 2011", como consecuencia de un problema concreto.

Se utiliza la comunicación para entrelazar vínculos con un grupo de personas que comparten la misma situación o conflicto de intereses. El problema se centra en la creación de una plataforma en defensa de unas oposiciones justas ante una serie de posibles irregularidades producidas en los procesos de selección para el acceso a la educación secundaria en Cataluña.

En este artículo se analizan los canales de información sobre los que se organizó este grupo, como plasmación concreta de las posibilidades reales, y las dificultades u obstáculos que han surgido cuando la comunicación discurre a través de las redes sociales. La creación y uso de grupos, blogs, difusión de 
mensajes en Facebook y Twitter, aportan una serie de ventajas a la fluidez de la comunicación, pero también tiene asociadas una serie de inconvenientes $u$ obstáculos que, en este caso, interesa observar.

A través de un análisis, centrado en la metodología de análisis de contenido, y observación directa, abordaremos en este artículo cuáles han sido los canales, las formas de comunicación y el flujo de los mensajes, en aras a lograr extraer de ello qué aspectos, en la comunicación en las redes sociales, aportan valor y efectividad a la comunicación, y qué otros aspectos, o factores, complican los procesos de comunicación.

En el mes de noviembre de 2011, el porcentaje de noticias que tratan sobre temas de redes sociales se divide, y refiere, a varios temas, tal y como recogemos en los porcentajes que se muestran en la tabla expuesta a continuación. Para su elaboración han sido consultados, como muestra, veinticinco noticias de máxima actualidad recogidas en cuatro medios de máxima tirada en prensa diaria española ${ }^{1}$.

Tabla 1: Temáticas en los diarios:

\begin{tabular}{|l|l|}
\hline Temáticas & $\%$ \\
\hline Política & 25,00 \\
\hline Personajes y eventos & 19,44 \\
\hline Privacidad, problemas legales & 16,66 \\
\hline $\begin{array}{l}\text { Movimientos sociales: 15M, Túnez, Ocupemos Wall Street, y } \\
\text { similares }\end{array}$ & 13,88 \\
\hline Opinión, reflexiones & 11,11 \\
\hline
\end{tabular}

\footnotetext{
${ }^{1}$ Periódicos consultados: El País, El Mundo, La Vanguardia y El Periódico (consulta 12 noviembre 2011).
} 
Tecnología, futuro de los medios

Fuente: elaboración propia

Actualmente estamos inmersos en una realidad mediática más omnipresente, difícil de comprender y dominar, puesto que desde hace una década, empezó a poner en entredicho el modelo dominado por los medios convencionales, construyéndose un nuevo modelo de comunicación, la comunicación interactiva, la comunicación en red. (Echazarreta, Martín, Vinyals, 2011).

A nivel general, los datos que se suelen tener en cuenta para analizar el nivel de interés de la comunicación es el referido a la inversión real estimada en Medios, de lo que podemos indicar que en 2009, en medios convencionales, alcanzó los 5.621,3 millones de euros, cifra que supone un decremento del $20,9 \%$ respecto a la registrada en el año anterior. Por segundo año consecutivo todos los medios presentan caídas en su cifra de negocio, con la excepción de Internet, donde el presupuesto en redes sociales y webs crece aun sigue creciendo (Infoadex, 2010).

Pero si pretendemos entender el éxito de estas nuevas formas de comunicación debemos tener en cuenta que muchos son los autores que hablan de la necesidad del ser humano por reunirse, agruparse en comunidades sociales, eso sí, sin olvidar mantener su identidad personal, exclusiva y desarrollando siempre nuestra propia personalidad. Esta necesidad de identificar lo que queremos realmente se puede plasmar, de manera idónea, en las redes sociales más especializadas, quizá esa sea la clave de parte de su éxito como agente socializador.

Las comunicaciones, a través de las redes sociales, nos muestran, con prontitud, sus dotes a favor de planteamientos democráticos, igualitarios y con una supuesta capacidad para conseguir y producir cambios en la sociedad. Sin embargo, se trata de acontecimientos difíciles de analizar, debido a la gran cantidad de elementos intervinientes. La primera dificultad consiste en poder 
acceder, de primera mano, a los cauces por los que discurrió la comunicación extendida a través de la red.

Paralelamente a estos grandes hechos, que han destacado en varios titulares durante todo el año 2011, la comunicación por las redes sociales ha servido, también, para organizar a personas que se habían encontrado de manera puntual con determinado tipo de problemas. En este contexto situamos el caso analizado en este artículo. Como consecuencia de un problema concreto, se utiliza la comunicación para entrelazar vínculos entre un grupo de personas que comparten la misma situación, o conflicto de intereses. El problema se centra en la creación de una plataforma en defensa de unas oposiciones justas ante una serie de posibles irregularidades, producidas en los procesos de selección para el acceso a la educación secundaria en Cataluña.

En este artículo se analizan los canales de información sobre los que se ha organizado el grupo de interés en este caso, como forma concreta de plasmar las posibilidades reales, y las dificultades u obstáculos que pueden surgir cuando la comunicación discurre a través de las redes sociales. El uso de grupos, blogs, difusión de mensajes en Facebook y Twitter,... aportan una serie de ventajas a la comunicación, pero también tiene asociadas una serie de dificultades u obstáculos que nos interesa observar. A través de un análisis centrado en la metodología de análisis de contenido y etnográfica, abordaremos en este artículo, cuáles han sido los canales, las formas de comunicación y el flujo de los mensajes, en aras a extraer de ello qué aspectos, de la comunicación en las redes sociales, aportan valor y efectividad a la comunicación, y qué otros aspectos, o factores, complican los procesos de comunicación.

Es importante conocer el hecho, por ejemplo, de que el $60 \%$ de los usuarios entra a su cuenta en Facebook diariamente. Un estudio de "Zed Digital", compañía especializada en marketing digital, señala que el $50 \%$ de los internautas son usuarios de redes sociales. (Martín, Echazarreta, Vinyals, 2010). 
Además, Buckingham (2005:43) nos alerta de que "ciertos cambios sociales y culturales contemporáneos están teniendo un impacto significativo en la naturaleza de las experiencias de las personas con los medios; y los educadores mediáticos no pueden ignorar estos cambios"

Estas nuevas formas de comunicación apuntan a que se considere el siglo XXI como el siglo de la revolución mediática, tecnológica, y con ello comunicativa, es una realidad que define los comienzos del sistema comunicativo y social de este comienzo de siglo.

Las nuevas tecnologías permiten nuevas y activas formas de comunicación, que han revolucionado el negocio comunicativo y publicitario, llegando los mensajes más allá del control de las audiencias. El receptor ahora es más libre, interactúa; no sólo es receptor, sino que se ha convertido en emisor y receptor de modo simultáneo. Este nuevo feed back hace que las nuevas tecnologías hayan favorecido la comunicación entre individuos. Ya no es una comunicación medio receptor, sino, receptor, receptor, siendo ambos emisores igualmente, lo que favorece una comunicación más fluida entre individuos.

Un mayor uso de las tecnologías como herramienta de comunicación ha revolucionado el negocio de la comunicación y la publicidad, pero sin duda y no menos importante, también las nuevas relaciones entre individuos, favorecido la comunicación masiva de modo rápido y eficiente llegando a ser agentes fuertemente influyentes en hechos sociales de importantes repercusiones.

\section{2.- Objeto, objetivos de estudio y metodología: análisis de un caso}

Pretender analizar la comunicación a través de las redes sociales, sería un objeto de estudio excesivamente amplio para ser abarcado de modo general en un solo estudio. Es posible que el análisis de un caso pueda ser el extremo opuesto; si bien, con ello, es más viable profundizar en los elementos y procesos intervinientes en la comunicación referida a un grupo de análisis concreto, tomado como referencia de partida para analizar las características de la comunicación en el seno de grupos sociales creados a través de las redes. 
El fenómeno de las redes sociales es relativamente reciente, no se cuenta todavía con un corpus teórico que permita establecer unas bases o cauces sólidos.

En esta investigación utilizaremos, como metodología básica, el análisis de contenido, aplicado al cuerpo de los mensajes intercambiados en la cuenta de correo electrónico, así como los creados a través de un grupo de difusión que aúna el intercambio de información entre los miembros del grupo que tienen un problema común y objetivos similares.

Como complemento a la investigación, se ponen en práctica los métodos de la observación participante, metodología etnográfica a través del análisis desde dentro del grupo, con lo que se combinan distintas técnicas de observación con un objetivo común: el análisis de los procesos de comunicación en el contexto de las redes sociales, en un caso concreto de movimiento social, de acuerdo con la teoría de los públicos de Dewey y Grunig, tal y como veremos.

\section{3.- Descripción del caso}

El caso que analizamos reúne una serie de requisitos que permiten considerarlo como un movimiento social. Surge a raíz de un problema concreto que afecta a un grupo amplio y variado de personas, con unos objetivos comunes; puesto que todos sus miembros se presentaron a las oposiciones de educación en la Comunidad Autónoma de Cataluña, España, en el año 2011.

De acuerdo con la teoría de Grunig (2000:228), las consecuencias -léase también problemas- las crean los públicos. Es decir, a raíz de un problema que afecta a varias personas, es posible que surja entre ellos un vínculo que los una, en principio focalizado en un problema concreto.

En la medida en que este problema, y las personas afectadas, es visible, las posibilidades de que el grupo de afectados se unan para intentar resolverlo son más factibles. Por el contrario, cuando un problema afecta a pocas personas, o no hay nexo de unión entre las mismas, y si además el problema no se hace visible a través de cualquier canal de comunicación que permita que las 
personas entren en contacto, el conflicto entra en lo que podríamos reconocer como "espiral del silencio".

Por lo tanto, antes de continuar con el análisis, es conveniente exponer los puntos básicos del problema, los públicos implicados, los motivos del conflicto; y a partir de aquí entrar en el tema central que trata este artículo, el análisis de los canales de comunicación utilizados, y los procesos de comunicación, con sus respectivos obstáculos y resultados conseguidos.

\section{1.- Concreción del problema}

La publicación de los resultados de las pruebas realizados por los candidatos fue el desencadenante de una reacción que no se quedó en el plano individual de cuantos habían recibido una valoración muy por debajo de sus expectativas y experiencia. La facilidad con que las personas hicieron uso de las redes sociales para expresar sus opiniones, comentarios, sirvió también para dar muestras de indignación ante cuestiones consideradas injustas.

El problema puede sintetizarse en la percepción de una valoración injusta, acuciada por un proceso de revisión en el que se dieron respuestas ambiguas y poco claras, la percepción de arbitrariedad en todo el proceso, junto a sospechas de favoritismo en algunos casos, y los rumores de que miembros de los tribunales habían recibido instrucciones para puntuar los trabajos limitadas a un bajo porcentaje de aprobados, creo el punto de unión y coincidencia de los miembros del grupo.

El grupo se creó a partir de la actuación de una sola persona que hábilmente aprovechó el momento de la publicación de las calificaciones para comunicar, a través de las redes sociales, su indignación ante una situación que potencialmente afectaba a un grupo de más de quince mil personas. El punto de salida, a nivel comunicativo, fue la publicación de unos breves mensajes en twitter $^{2}$ y la creación de un perfil en facebook ${ }^{3}$ en el que expresaba su opinión,

\footnotetext{
${ }^{2}$ Hashtag; indignatsopos

${ }^{3}$ http://www.facebook.com/\#!/groups/200358050015369/
} 
y hacía un llamamiento a quienes estuvieran en una situación parecida, a adherirse al grupo creado.

Analizaremos así, el potencial de estas herramientas para enlazar, establecer contactos y viralidad; así como su capacidad para producir procesos de comunicación completos, de intercambio de contenidos, que permitan reflexionar y conducir a determinado tipo de acciones o actuaciones.

\section{2.- La utilización de herramientas, canales y plataformas de comunicación}

A partir del momento en que parece que puede ser necesario intercambiar datos más concretos, y evitar que la información se pierda a través de redes dispersas, es cuando se hace necesario canalizarlo a través de la utilización de una cuenta de correo electrónico y un grupo.

Paralelamente, y de forma intuitiva, conscientes, también, de la utilidad de los medios de comunicación convencionales, se ofrece la noticia a distintos medios de comunicación en un momento casualmente favorable, (pero con menor notoriedad) para la publicación de noticias, debido al comienzo del periodo estival, como es el mes de julio. Los argumentos aportados por el grupo de profesores en su reivindicación a favor de un proceso de oposiciones justas fueron publicados en los siguientes medios: ADN, Diario de Girona, La Directa, Diario de Tarragona, y varios blogs.

La publicación de las reivindicaciones, en forma de noticia, es uno de los elementos que serán clave para comprender los procesos de comunicación que se realizaron dentro del grupo, a través del análisis de los mensajes enviados al grupo, para su difusión, así como los enviados en la cuenta de correo electrónica desde la que se gestionaba la comunicación.

En el análisis, hemos tenido en cuenta que algunos hechos fueron decisivos en el impulso de la viralidad, pues se produjo una importante ampliación del grupo de personas, que rápidamente paso de "pocos" a cerca de dos centenares. Del mismo modo, será también relevante recoger algunos datos sobre la relación de las personas con el problema, con el fin de observar si 
había posibilidades de difundir el mensaje a personas de su grupo de amistades o conocidos, hecho estrechamente relacionado con la forma en que habían afrontado el proceso de preparación de las oposiciones, bien de manera individual ( y no compartían el problema), o en grupos de trabajo (donde el problema se compartía, aumentando así los intervinientes en el grupo).

\section{4.- Análisis de los procesos de comunicación}

La observación de los procesos de comunicación se puede ordenar en distintas fases. Primeramente, en este caso, se utilizó Facebook y Twitter; en la segunda, inmediata a la anterior, el blog ${ }^{4}$. En una tercera el correo electrónico, y el grupo de discusión vinculado al correo. Cada una de estas fases coincide con la utilización de un soporte de comunicación distinto.

La utilización de Facebook y Twitter, en el caso analizado, fue inicial y puntual; de modo que no se "explotó" al máximo su potencial, dejándose rápidamente en desuso. El perfil de Facebook acumuló rápidamente el centenar de personas, aunque la gestión de la comunicación se dispersó, de forma que dejó de ser útil para conseguir contactos cualificados, directamente relacionados con atraer el interés del público relacionado con la defensa de unas oposiciones justas.

La fase que más nos interesa analizar es la tercera, en la que se utiliza el soporte de comunicación más tradicional, dentro de los analizados, como es el correo electrónico, especialmente, el grupo de difusión ${ }^{5}$ vinculado al mismo, puesto que permitió la comunicación fluida en el grupo. En este punto la productividad, es decir, el volumen de información y mensajes generados, empieza a tener una dimensión considerable, siendo cada vez más difíciles de gestionar.

\footnotetext{
${ }^{4}$ Oposiciones justas: oposicionsjustes.blogspot.com

${ }^{5}$ oposicionsjustes.googlegroups.com
} 
De la observación efectuada se ponen de manifiesto una serie de errores. En primer lugar, los títulos de los mensajes no siempre son lo suficientemente claros para articular a su alrededor los mensajes relacionados con el tema principal. Además, la confusión de algunas personas, entremezcla mensajes o comentarios con temas que no están relacionados, lo que genera interferencias, además de frenar el posible hilo conductor de cada tema.

Es difícil lograr total concordancia, dentro de usuarios de un grupo espontáneo, en la utilización eficiente y el aprovechamiento que supondría una comunicación bien estructurada, centrada en los temas y delimitándolos frente a otros; con aportaciones que se sepan concretar los temas relevantes, manteniéndolos al margen de los meros comentarios que, no por ello, deben evitarse, pues cumplen la función fática, aunque sea a tiempo diferido.

De esta forma, observamos que en la primera etapa de la tercera fase, de una duración de veintiún días, se produce una interactividad efectiva, un flujo de ida y vuelta de la información, con lo que se alcanzan los objetivos iniciales: redacción de un manifiesto con las aportaciones y puntos de vista de la mayoría de los miembros del grupo; y la redacción de un recurso colectivo en denuncia de una serie de posibles irregularidades en el proceso de las oposiciones.

El primer punto de inflexión coincide con la fase posterior al cumplimiento de los primeros objetivos, momento en el que empiezan a acumularse mensajes. A partir de entonces, se observa un interés decreciente. Por un lado, después de la presentación del recurso, se crea un espacio de "espera" hasta que se resuelva o deniegue éste, por silencio administrativo. Un tiempo que va en contra del impulso inicial. Se empiezan a recibir correos que solicitan darse de baja para evitar recibir correos que ya no les aportan nueva información.

Podemos observar los índices de utilización de los envíos de correos electrónicos, desglosados por fechas, en los siguientes gráficos:

Grafico 1: Índices de utilización de envío de correos 

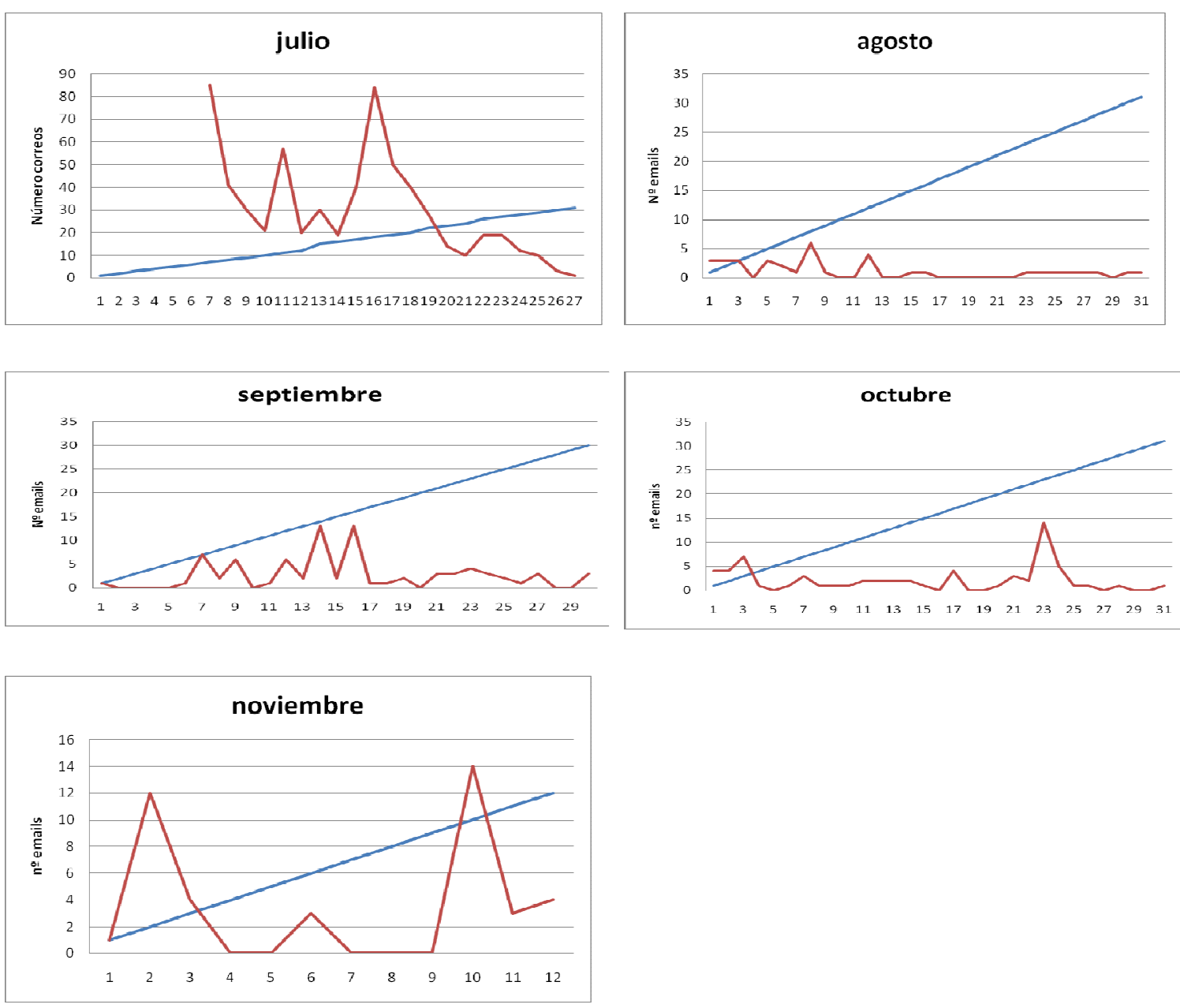

Fuente: elaboración propia

En lo que respecta al grupo de discusión, las solicitudes de altas de nuevos usuarios, destinatarios de los mensajes, reflejan que el interés en darse de alta se concentra en la fecha de 20 y 21 de julio, coincidiendo con la publicación, en prensa escrita, de una noticia que pone en conocimiento la creación del grupo y la dirección del blog.

Gráfico 2: altas en el grupo de difusión 


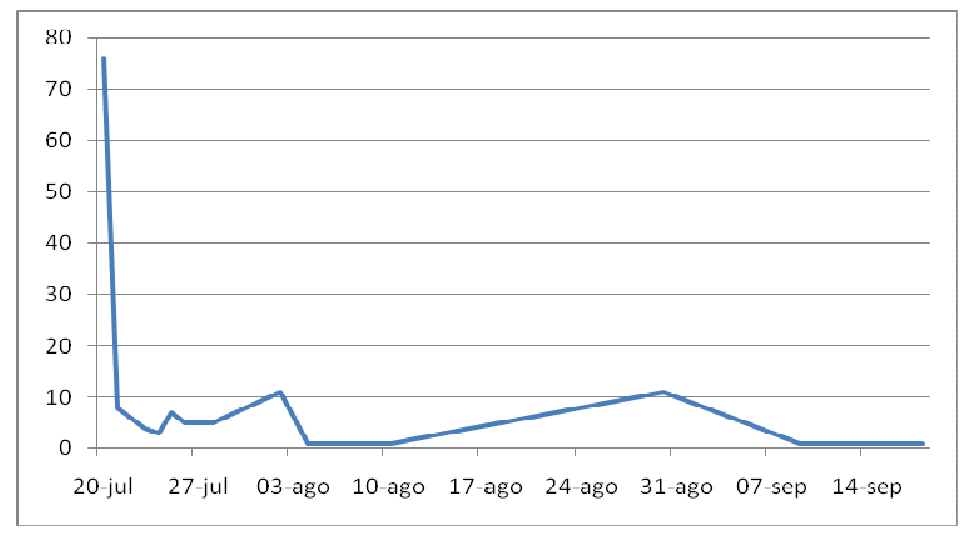

Fuente: elaboración propia

El desglose de las participaciones en el grupo de difusión muestra como el 70\% de los mensajes están concentrados en las diez primeras personas. En la tabla siguiente se puede observar el número de mensajes ordenados en orden del número de participaciones por usuario y mes:

Tabla 2: Numero de mensajes por participante.

\begin{tabular}{|c|c|c|c|c|c|}
\hline & $\begin{array}{c}\text { Ranking } \\
\text { participaciones }\end{array}$ & Julio & Agosto & Sept. & Octubre \\
\hline 1 & 180 & 92 & 4 & 68 & 16 \\
\hline 2 & 56 & 18 & 2 & 27 & 9 \\
\hline 3 & 52 & 31 & 16 & 5 & 0 \\
\hline 4 & 41 & 0 & 0 & 20 & 21 \\
\hline 5 & 34 & 6 & 2 & 15 & 11 \\
\hline 6 & 28 & 17 & 0 & 7 & 4 \\
\hline 7 & 24 & 23 & & & 1 \\
\hline 8 & 23 & 15 & 2 & 3 & 3 \\
\hline 9 & 23 & 23 & 0 & 0 & 0 \\
\hline 10 & 20 & 11 & 2 & 3 & 4 \\
\hline
\end{tabular}

Fuente: elaboración propia.

En la siguiente se puede observar, según la temática, el número de publicaciones en el grupo, distribuidas por meses: 
Tabla 3: Publicaciones distribuidas por meses:

\begin{tabular}{lc}
\hline Julio & 485 \\
\hline Agosto & 69 \\
Septiembre & 244 \\
octubre & 189 \\
\hline
\end{tabular}

Fuente: elaboración propia.

La tabla siguiente muestra el desglose de los mensajes en función de la temática que trata cada uno de ellos:

Tabla ํo 4: Desglose por temática

\begin{tabular}{lr}
\hline Temática & № mensajes \\
\hline Asamblea, reuniones & 287 \\
\hline Temas jurídicos & 104 \\
\hline Reclamaciones & 48 \\
\hline Renovación del compromiso, motivación, contra el & 22 \\
desánimo & 12 \\
\hline Bajas & 8 \\
\hline Información, enlaces... & 90 \\
\hline Propuesta de actividades, organización & 66 \\
\hline Difusión en los medios de comunicación, noticias & 110 \\
\hline Recursos, impugnación & \\
\hline Recogida de firmas & \\
\hline
\end{tabular}




\begin{tabular}{lc}
\hline Defensor pueblo, sindico agravios & 14 \\
\hline Sindicatos & 60 \\
\hline Comunicación de irregularidades tribunales oposición & 18 \\
\hline Mensajes de soporte, manifiesto & 130 \\
\hline Estadísticas, cuestionarios & 7 \\
\hline Temas de gestión y organización & 87 \\
\hline Exposición de casos individuales & 78 \\
\hline Escritos de denuncia, cartas & 86 \\
\hline Reclamaciones & 104 \\
\hline
\end{tabular}

Fuente: elaboración propia.

Además de este análisis, se distribuyeron dos correos electrónicos que contenían un enlace que permitía responder a dos cuestionarios. El primero de ellos en fecha 17 de septiembre, al que respondieron 40 personas de las presentadas a las oposiciones de educación. De entre ellas, 14, el 35\% personas, se habían presentado por primera vez en esta convocatoria, once personas en dos convocatorias anteriores, dos a tres anteriores, y 3 a más de tres convocatorias. De ellas, el $35 \%$ presentaron recurso individual; y el $62,5 \%$ el recurso colectivo.

En la preparación de las oposiciones, sólo el 27,5\% de personas participó en grupos de trabajo, y el $70 \%$ no lo hizo.

En relación a la preparación, las consultas en Internet para conseguir material de preparación, y las respuestas, ponen en evidencia que la información que se encuentra en Internet está mayoritariamente relacionada con información comercial de editoriales y academias; apenas se encuentran grupos de personas abiertos a la colaboración. 
Al segundo cuestionario, centrado en los procesos de comunicación, se respondió el 7 de octubre de 2011. El análisis de las respuestas pone de manifiesto que la mayoría de las personas reconocen recibir información de los temas en los que tienen interés (86\%), y rechazan aquella que no les interesa. También se observa un moderado uso de los sistemas para seleccionar los contenidos que interesan respecto los que no interesan (16\%).

Se observa una dispersión de opiniones, en relación a la recepción de mensajes del google groups, al igual que en el correo electrónico, donde se mezcla información útil con información irrelevante.

Al $67 \%$ le molesta recibir correos electrónicos respecto a temas que no ha solicitado o pedido expresamente. El $50 \%$ manifiesta que cuando recibe un correo electrónico de alguien desconocido no lo responde; y en el $45 \%$ de casos ni tan siquiera lo abre.

Respecto la valoración del grado de utilidad de las comunicaciones en Internet para que las personas se organicen en intereses comunes, un $85 \%$ lo valora positivamente. En esta línea, Facebook es valorado por el 28,57\%, los foros por $21,43 \%$, los blogs por 21,43\%, siendo Twitter valorado por 7,14\%; con un elevado no sabe, no contesta, $(35,71 \%$ de los encuestados).

Cuando se les pregunta si consideran que hay aspectos de la comunicación dentro del grupo que han fallado, hay una gran dispersión en las respuestas, que oscilan entre los que consideran que no ha fallado $28 \%$ (entre 4 y 5 puntos, levemente) y las que si ha fallado $54 \%$, entre 6 y 7 puntos.

Asimismo, se interroga en relación a si la comunicación en las redes puede tener deficiencias, a lo que responden favorablemente el 35,71\%. Durante el mes de julio, la mayoría de las personas, reconocen haber leído la totalidad de los mensajes que se recibieron, un $47 \%$. Pero reconocen que a partir de septiembre, disminuyó (al 35\%), tal como se observó también en el primer bloque de gráficos. 


\section{Comunicación dirigida versus comunicación espontánea}

Hay una gran diferencia entre la comunicación transmitida e través de las redes, podemos distinguir entre la que está dirigida por una empresa 0 institución, llevada a cabo por profesionales, cuyo fin es conseguir unos objetivos, y la que se hace de forma espontánea, no planificada, cuyo único objetivo es crear contenidos con el fin de compartir problemas o inquietudes, creada por parte de personas individuales o pequeños colectivos no organizados, sin experiencia ni recursos para planificar la comunicación.

Quizás confunda el hecho de que en las redes sociales ambos comparten un mismo espacio y un lenguaje que se asemeja a un diálogo en igualdad de posiciones; con formas de comunicación que nos puedan dar la sensación de que tienen canales de ida y vuelta.

La comunicación que llevan a cabo las empresas e instituciones es una comunicación que parte de la investigación y la observación de la conducta de los destinatarios de la misma. Tanto los contenidos como la forma y diseño de los mismos están orientados a la consecución de objetivos. Para hacerlo cuentan con recursos de todo tipo, y gracias a la medición de los resultados, se retroalimenta en un proceso de actualización constante.

Los mensajes y contenidos publicados por personas individuales, o pequeños grupos, generalmente no organizados, en las redes sociales, suponen un gran volumen de contenidos, de los que consiguen destacar un porcentaje muy reducido. Se trata de mensajes que se crean de forma espontánea, no premeditada, y que sirven para expresar inquietudes, el interés o la oposición en relación a determinados temas. La inmediatez de estos mensajes les da una permanencia muy fugaz, aunque algunos de estos mensajes consiguen sobrevivir y desplazarse, de usuario a usuario, a través de las redes sociales.

\section{6.- Conclusiones}

Existen grandes diferencias en la forma y el contenido de la comunicación cuando sus emisores son empresas o instituciones, o bien cuando se trata de personas individuales o pequeños grupos, salvo excepciones concretas. La 
utilización del caso analizado no pretende su extrapolación a otros, si bien podemos extraer indicios que servirán de base para llevar a cabo una observación de fenómenos similares y deducir posibles tendencias en los procesos de comunicación en el seno de las redes sociales.

Las comunicaciones realizadas por parte de personas individuales o en pequeños grupos no organizados institucional o empresarialmente, se caracteriza por ser intuitiva, inmediata, realizada sin un análisis previo y sin una planificación de su posible alcance o repercusión. Por el contrario, para las empresas o instituciones no tiene sentido difundir una comunicación que no haya sido debidamente planificada, investigada y sopesada.

Las personas individuales suelen establecer un paralelismo entre distintos niveles de comunicación, sin diferenciar apenas lo que sería la comunicación de pensamientos y opiniones de forma espontánea o coloquial, con otro nivel de comunicación con alcance más amplio y conocimiento público.

Las organizaciones son conscientes de la necesidad de efectuar un seguimiento de la comunicación, así como de una investigación previa y posterior, que retroalimenta el contenido y forma los sucesivos mensajes, que serán cada vez más elaborados y adaptados al posible receptor, con el fin de para poder funcionar adecuadamente en los procesos de comunicación en red, consiguiendo los objetivos de la comunicación, en este caso estratégica.

Para las empresas o instituciones, o colectivos organizados, la comunicación es una herramienta de gestión que transmite un conjunto de valores identitarios y culturales, como resultado de mensajes concretos que en cada caso se puedan publicar. En cambio, pocas son las personas que tienen en cuenta estos aspectos en el diseño de sus mensajes. Las herramientas que se utilizan más en las redes sociales permiten una gran rapidez e inmediación en la publicación de cualquier tipo de mensajes, por lo que es difícil que un particular tome consciencia de que cada mensaje entra en un complejo proceso de selección por parte del inmenso número de mensajes que recibe el posible destinatario. 
Las empresas e instituciones, en cambio, conscientes de esta dificultad, investigan, estudian y diseñan mensajes y adecuan su comunicación teniendo en cuenta las características que hacen que los mensajes sean efectivos y alcancen una gran cobertura en las redes.

Entre los factores que permiten que haya dos formas tan distintas de gestionar la comunicación están los objetivos que unos y otros pueden tener, y los recursos para conseguirlos. En general, una empresa o institución contará con un presupuesto que destinará a investigación, diseño y seguimiento de sus comunicaciones, lo que redunda en una planificación de un trabajo, al que se le exige un retorno.

También se encuentran diferencias en el contenido y en la estructuración de los mensajes. Frente a mensajes prácticamente espontáneos y no estructurados, las empresas trabajan tanto el contenido como la forma, y tienen en cuenta las características de los canales por los que circulará su comunicación.

Canales como Facebook o Twitter se retroalimentan constantemente de mensajes emitidos de forma espontanea, inmediata, conectada en el momento, en lo que el emisor puede pensar o sentir en un momento dado. Contienen un alto componente emocional, frente al supuestamente racional que podría tener un emisor empresarial. Sin embargo, éste último, utiliza la investigación, el conocimiento y la experiencia para dar una forma similar a sus mensajes de la que tendría un mensaje creado de forma espontánea, habiendo previamente analizado cuales son los elementos que, en este tipo de mensajes, permiten ser eficaces en relación a los objetivos que con ello se desean alcanzar.

La gestión de una comunicación que se proponga ser eficaz precisa de un esfuerzo no tan sólo económico, sino también de dedicación o tiempo. En la observación del contenido, forma y estructuración de los mensajes que, un grupo como el analizado intercambia, se aprecia que se pierden por el camino parte del contenido de los mensajes, con lo que se pierde el enlace entre comunicación y acción. 
La falta de liderazgo es uno de los principales problemas que se observan en la comunicación que pretende ser, y en algunos casos es, horizontal. En una empresa o institución, por el contrario, existe un liderazgo inherente a las estructuras internas de cada organización, suficientes para que no se produzcan errores básicos como no leer todos los mensajes, gestionando bien los datos o información que contienen, y canalizarlos para tomar decisiones.

En el caso analizado, se observa como el déficit en la gestión de la comunicación es el desencadenante de que, a partir de un momento, la comunicación esté dando vueltas en círculo, sin que se resuelvan algunos de los puntos básicos o temas que podían haber sido decisivos para tomar decisiones y actuar. Este fenómeno no suele ocurrir en la fase inicial, cuando las personas que se adhieren al grupo están más motivadas y asimilan bien todos los mensajes y les dan el cauce que consideran oportuno. Pasado de un mes, el número de mensajes que han recibido son ya más amplios que los que pueden atender por su disponibilidad de tiempo e interés, lo que deriva en una acumulación de mensajes que se atienden parcialmente, con el cansancio inherente y con la sensación de que la comunicación no fluye de acuerdo con lo que cada persona estima pertinente y adecuado a sus objetivos.

A partir de esta segunda fase, la gestión de la comunicación puede acarrear más inconvenientes que aspectos positivos. Se observa que en un grupo no estructurado la lectura de los mensajes es, en general, un tanto aleatoria, con excepciones relacionadas con mensajes que llamen la atención o contengan una apelación directa relacionada con los temas que vinculan a cada persona con el grupo. Sin embargo, persiste la desconexión entre comunicación y acción. Esto explicaría que los grupos funcionen bien durante la fase de creación, pero entren rápidamente en una segunda fase en la que los problemas relacionados con la gestión de la comunicación, con el escuchar y el proponer, estén en equilibrio.

Por tanto para que la comunicación a través de las nuevas tecnologías se convierta en una herramienta realmente eficiente a la hora de resolver nuestros problemas, es necesario utilizarla con criterio y rigor, pues de lo contrario el 
volumen de información desborda los objetivos y la convierte en comunicación ineficiente, quizá por ello el entusiasmo mismo de comunicar a través de las redes sociales es el principal problema para canalizar adecuadamente un problema en ánimo a su posible solución. Este es quizás uno de los elementos clave: el conocimiento y experiencia en la gestión de la comunicación se instrumentalizan para conseguir unos objetivos determinados. Cuando no se es consciente de la importancia de ello, la comunicación fluye desbocada y es poco eficaz para conseguir objetivos.

\section{7.- Bibliografía}

Bardin, L.(1986) Análisis del Contenido, Akal, Madrid.

------ Analyse de Contenou, P.V.F, Paris, 1977.

Buckingham, D. (2005): Educación en medios. Barcelona, Paidós. [1a. edición en inglés, 2003]

British Film Institute (2010): "Moving Images in the Classroom", Londres, British Film Institute.

British Film Institute (2010): "Moving Images in the Classroom", Londres, British Film Institute.

Critto, A.(1982). El método científico en las ciencias Sociales, Paidós, Buenos Aires,

Eguizábal R.(1990) El análisis del mensaje publicitario: España. Tesis Doctoral. Universidad Complutense de Madrid.

Grunig, J.E. y Hunt, T. (2000): Dirección de relaciones públicas. Gestión 2000. Barcelona.

Hazan, M. ; Dorfman, M.; et all, (2009) El modelo de la nueva agencia. Edición Digital .

Echazarreta C., Martín Casado T.G., Vinyals M., (2011). "Educar desde los medios en el siglo XXI: las Series de Ficción Juvenil”, en: Educación mediática y competencia digital, (Aparici R. García Matilla A. Gutiérrez A.)Ed: E.U. de Magisterio(UVA). 
Martín Casado T.G., Echazarreta C., Vinyals M. (2010), "Nuevos medios, nuevos formatos, nuevas necesidades para alcanzar el éxito en la publicidad interactiva" en Congreso Internacional sobre nuevas formas de comunicación. Universidad Jaime I de Castellón.

Martín Casado,T.G. (2010). El tratamiento de género en la creación del mensaje publicitario del medio prensa en el siglo XXI. España. Tesis Doctoral. Universidad Complutense de Madrid.

VV.AA. (2010) Estudio en España de la inversión publicitaria en España 2010. [en línea] http://www.infoadex.es/RESUMEN\%2010.pdf, visitado 12/11/2011.

Para citar este artículo:

Echazarreta, Carmen - Vinyals, Manel - Gema Martín, Teresa (15-12-2011). EFICACIA E INEFICACIA DE LA COMUNICACIÓN HORIZONTAL EN LOS MOVIMIENTOS SOCIALES. CASO ANÁLISIS: "OPOSICIONES JUSTAS EN CATALUÑA 2011".

REDMARKA - CIECID - Unidad de Investigación en Marketing Aplicado-Universidad de A Coruña

Año IV, Número 7, V3, pp.37-59

ISSN 1852-2300

URL del Documento: cienciared.com.ar/ra/doc.php?n=1602

URL de la Revista: cienciared.com.ar/ra/revista.php?wid=39 